\title{
Crack growth rates and microstructure feature of initiation region for very-high-cycle fatigue of a high-strength steel
}

\author{
Yuanpei $\mathrm{Hu}^{1,2}$ | Chengqi Sun ${ }^{1,2}$ | Youshi Hong ${ }^{1,2}$ (D)
}

\author{
${ }^{1}$ LNM, Institute of Mechanics, Chinese \\ Academy of Sciences, Beijing 100190, \\ China \\ ${ }^{2}$ School of Engineering Science, \\ University of Chinese Academy of \\ Sciences, Beijing 100049, China

\section{Correspondence} \\ Y. Hong, LNM, Institute of Mechanics, \\ Chinese Academy of Sciences, Beijing \\ 100190, China. \\ Email: hongys@imech.ac.cn

\section{Funding information} \\ Strategic Priority Research Program of the \\ Chinese Academy of Sciences, Grant/ \\ Award Numbers: XDB22020201 and \\ XDB22040503; National Natural Science \\ Foundation of China, Grant/Award \\ Number: 11572325
}

\begin{abstract}
The S-N data up to very-high-cycle fatigue (VHCF) regime for a high-strength steel were obtained by fatigue tests under constant amplitude and variable amplitude (VA) via rotating bending and electromagnetic resonance cycling. Crack initiation for VHCF was from the interior of specimens, and the initiation region was carefully examined by scanning electron microscopy and transmission electron microscopy. Crack growth traces in the initiation region of fine-granular-area (FGA) were the first time captured for the specimens under VA cycling by rotating bending. The obtained crack growth rates in FGA were upwards to connect well with those in fish-eye region available in the literature and were associated well with the calculated equivalent crack growth rates in FGA. The observations of profile samples revealed that FGA is a nanograin layer for the specimens under VA cycling, which is a new evidence to support the previously proposed "numerous cyclic pressing" model.
\end{abstract}

\section{KEYWORDS}

crack growth rate, crack initiation, fine-granular-area, high-strength steel, variable amplitude loading, very-high-cycle fatigue

\section{1 | INTRODUCTION}

Fatigue failures of engineering materials and structures beyond $10^{7}$ cycles may happen in railway, aircraft, ship, and other engineering structures. ${ }^{1}$ The topic of very-high-cycle fatigue (VHCF) which is defined as the fatigue failure beyond $10^{7}$ loading cycles has attracted the interest of researchers, and an increasing number of investigations on VHCF have been carried out to satisfy the needs of social development in recent decades. ${ }^{2-7}$ The behavior of crack initiation and early growth for VHCF is different from that of low-cycle fatigue (LCF) and high-cycle fatigue (HCF). For LCF and most of HCF cases of metallic materials, fatigue cracks initiate from the specimen surface due to persistent slip bands, whereas for VHCF, cracks usually initiate from the interior of material at non-metallic inclusions or other inhomogeneities. $^{8-13}$

Nomenclature: Area, projection area of inclusion or FGA; d $a / \mathrm{d} N$, crack growth rate; $D_{\mathrm{f}}$, total cumulative damage; $D_{\mathrm{H}}, D_{\mathrm{L}}$, cumulative damage under high stress and low stress; $f$, loading frequency; $n_{\mathrm{H}}, n_{\mathrm{L}}$, loading cycles under high stress and low stress; $N_{\mathrm{f}}$, number of cycles to failure; $N_{\mathrm{Hf}}, N_{\mathrm{L}}$, median fatigue life corresponding to high stress and low stress; $r$, distance from the center of crack origin to the middle point of a crack trace; $r_{\mathrm{p}}$, plastic zone size at crack tip; $R$, stress ratio; $\Delta \sigma_{\mathrm{a}}$, stress amplitude; $\Delta a$, width of crack growth trace; $\Delta K$, stress intensity factor range; $\Delta K_{\mathrm{FGA}}$, stress intensity factor range of FGA; $\Delta K_{\mathrm{th}}$, threshold $\Delta K$ of crack propagation; $\nu$, Poisson ratio; $\sigma_{\mathrm{H} \text {, max }}, \sigma_{\mathrm{L} \text {, max }}$, the maximum stress of high and low stress cycling; $\sigma_{\mathrm{y}}$, yield stress; CA, constant amplitude; ER, electromagnetic resonance; FGA, fine-granular-area; FiE, fish-eye; FIB, focused ion beam; HCF, high-cycle fatigue; Inc, inclusion; LCF, low-cycle fatigue; NCP, numerous cyclic pressing; RB, rotating bending; SAD, selected area electron diffraction; SEM, scanning electron microscopy; SIF, stress intensity factor; TEM, transmission electron microscopy; VA, variable amplitude; VHCF, very-high-cycle fatigue 
For crack initiation from the interior of specimen in VHCF, the fracture surface usually presents a fish-eye (FiE) morphology containing a "fine-granular-area" $(\text { FGA })^{14}$ (also called "optical-dark-area"15 or "granular-bright-facet"16) surrounding an inclusion or grain boundary as crack origin, and almost all the fatigue life (more than $95 \%$ of total life) is consumed in the region of FGA. ${ }^{17}$ Because nonmetallic inclusions are the crack origins for most VHCF cases with interior crack initiation, the effects of the inclusions on the behavior of VHCF have been intensively investigated, and the influential parameters are their size, elastic properties, and adhesion to the matrix. ${ }^{18}$ FGA and FiE are regarded as the characteristic regions of crack initiation for VHCF. ${ }^{17}$ Several models have been proposed to explain the formation mechanism of FGA, including "hydrogen assisted crack growth", ${ }^{19,20}$ "decohesion of spherical carbide", 8 "formation and debonding of fine granular layer", 4,21 "local grain refinement at crack tip and debonding", ${ }^{22}$ and "vortical plastic flows to produce nanostructure layer and debonding". ${ }^{23}$ Each of these proposed mechanisms encountered difficulties for more general cases. Based on the latest results that the morphology of FGA only existed at negative stress ratio cases but not at positive stress ratio cases for high-strength steels and titanium alloys, Hong et $\mathrm{al}^{24-26}$ proposed the mechanism of numerous cyclic pressing (NCP) to explain the formation process of crack initiation characteristic region of FGA. First, crack initiation appears at the interface between inclusion and matrix after an initial number of loading cycles, and nanograins form at crack wake due to localized plastic deformation resulted from the repeated pressing between crack surfaces, which is associated with the effect of crack closure ${ }^{27,28}$ and the relaxation of residual stress. ${ }^{29,30}$ Then, with the increase of loading cycles, a nanograin layer gradually presents in previous crack surfaces and nanograins form in new crack surfaces. At last, the NCP process terminates to form the critical size of FGA. The proposed NCP model regards that the formation of nanograins in the crack initiation region for VHCF needs 2 conditions: (1) the compression loading that results in the contacting between the surfaces of originated crack, and (2) the sufficient number of loading cycles that ensures the enough contacts (ie, severely localized plastic deformation) between the crack surfaces. If such conditions are not fulfilled, the FGA morphology with greatly refined grains is unlikely to be produced.

The new results on structural steels ${ }^{31}$ and titanium alloys $^{25}$ have again validated the NCP model..$^{24,26}$ Note that the reported results of FGA being a nanograin layer under negative stress ratios were all subjected to constant amplitude (CA) cycling. It will be interesting to know what will happen for the case subjected to variable amplitude (VA) cycling.

Although the mechanism of crack initiation in VHCF has been in-depth investigated, the process of crack initiation and the related crack growth rate in FGA region are still unknown issues. In an early result estimated by Murakami et al, ${ }^{15}$ the crack growth rate in the FiE region of an SCM435 steel was in the order of magnitude of $10^{-11}$ to $10^{-12} \mathrm{~m} /$ cycle. For this small value much less than 1 lattice spacing, they simply explained that the crack in the FiE region was not propagating in every loading cycle. Another early result estimated by Tanaka et $\mathrm{al}^{32}$ reported the crack growth rate in the initiation region in VHCF for an SUJ2 steel was below $10^{-12} \mathrm{~m} /$ cycle. The growth value for each cycle was again much less than Burgers vector, for which they argued that the process of crack initiation was non-uniform along the crack perimeter and the dislocation mechanism for crack growth was no longer effective. Recently, Hong et $\mathrm{al}^{17}$ used Paris equation to calculate the fatigue life from the boundary of FGA to that of FiE, and that from FiE to the critical boundary given by fracture toughness thus to obtain the fatigue life in the FGA region of a high-strength steel. They estimated the crack growth rates in the FGA region being in the order of magnitude of $10^{-12}$ to $10^{-13} \mathrm{~m} /$ cycle when the fatigue life was between $10^{7}$ and $4 \times 10^{8}$ cycles. All above data of crack growth rates were equivalent crack propagation rates in the FGA region, estimated from the related fatigue life but not from the direct observation of fatigue crack growth process.

There have been several experimental efforts for the purpose of direct observation of fatigue crack growth in the initiation region of VHCF. Stanzl-Tschegg et $\mathrm{al}^{33}$ measured the crack growth rates of tubular specimens with a sharp notch in ambient air and vacuum for a $12 \%$ chromium steel, with the results of the crack growth rate of $5 \times 10^{-13} \mathrm{~m} /$ cycle in vacuum and $6 \times 10^{-12} \mathrm{~m} /$ cycle in ambient air. They compared the fracture surface morphologies of the tubular specimens with those of crack interior initiation in VHCF therefore to estimate the crack growth rates: approximately $10^{-12} \mathrm{~m} /$ cycle in FGA region, approximately $10^{-11} \mathrm{~m} /$ cycle in FiE (outside FGA) region and above $10^{-9} \mathrm{~m} /$ cycle in the region outside FiE. More interesting examples of crack growth detection at initiation region took advantage of VA cycling, in which crack growth traces were possible to appear in the initiation and early growth region due to the variation of the applied maximum stress. Ishida et $\mathrm{al}^{34}$ and Ogawa et $\mathrm{al}^{35}$ detected the crack growth traces in the FiE area (outside FGA) called beach marks for an SUJ2 steel subjected to repeated 2-step amplitude loading, but no crack growth evidence was observed in the FGA 
region. The obtained fatigue crack growth rates by the beach marks in the FiE region were in the range from $10^{-7}$ to $10^{-9} \mathrm{~m} /$ cycle, and the equivalent crack growth rates in the FGA region were in the range from $10^{-13}$ to $10^{-14} \mathrm{~m} /$ cycle, which were estimated from the radii of FGAs and the total fatigue life. Muller et $\mathrm{al}^{36}$ and Sander et $\mathrm{al}^{37,38}$ also captured the crack growth traces called arrest marks in the FiE area (outside FGA) for a high-strength structural steel under VA loading, and the obtained crack growth rates in the FiE area were in the range from $3 \times 10^{-11}$ to $2 \times 10^{-12} \mathrm{~m} /$ cycle. The above examples indicate that VA loading is a promising approach to directly detect and measure the crack growth rates in the crack initiation region of VHCF. However, the previous investigations ${ }^{34-38}$ were only able to capture the crack growth traces in the FiE area outside FGA. Up to now, no observations of crack growth traces in FGA region were reported in the literature. It is obvious that the observation of crack growth evidence in the FGA region is extremely important because it is the key point for understanding the formation mechanism of crack initiation region of VHCF.

In this paper, fatigue tests up to $\mathrm{VHCF}$ regime for a high-strength steel were conducted by $\mathrm{CA}$ and VA cycling via rotating bending (RB) and axial cycling with electromagnetic resonance (ER) method. The fractography of failed specimens in the VHCF regime was observed by scanning electron microscopy (SEM). Crack growth traces in FGA were the first time captured under VA cycling by RB method, which allows one to calculate the crack growth rate in the FGA region. Moreover, the micro-morphologies of crack initiation regions were carefully examined by transmission electron microscopy (TEM) with selected area electron diffraction (SAD) detection on the profile samples prepared by focused ion beam (FIB) cutting. The observations revealed that a layer of nanograins presents in the FGA region for the specimens under VA cycling, which is a new evidence to support the previously proposed NCP model. In addition, the appearance possibility of crack growth traces was discussed in terms of stress intensity factor (SIF) range as well as the plastic zone size at different locations of FGA, and in terms of the contacting between related crack surfaces.

\section{2 | TEST MATERIAL AND EXPERIMENTAL PROCEDURE}

\section{1 | Test material}

The test material in this investigation is a high carbon chromium steel (GCr15) with the chemical composition (wt.\%) of $1.00 \mathrm{C}, 1.52 \mathrm{Cr}, 0.31 \mathrm{Mn}, 0.21$ $\mathrm{Si}, 0.0086 \mathrm{P}, 0.016 \mathrm{~S}$, and Fe balance. The specimens were heated at $845^{\circ} \mathrm{C}$ in salt-bath furnace for 10 minutes and oil-quenched then tempered at $200^{\circ} \mathrm{C}$ in vacuum for 2 hours. The microstructure of the test material is tempered martensite as shown in Figure 1. The tensile strength of the material was $2425 \mathrm{MPa}$, and the yield strength was $1764 \mathrm{MPa}$ from the tensile test on 4 cylindrical specimens with the diameter of $5 \mathrm{~mm}$ in gage section, and the micro-hardness was $754 \mathrm{Hv}\left(\mathrm{kgf} / \mathrm{mm}^{2}\right)$ measured by a micro-hardness tester at a load of $500 \mathrm{gf}$ with the load holding time of 15 seconds.

\section{2 | Fatigue test methods}

Fatigue tests were conducted by both CA and VA cycling (repeated 2-step loading) with an RB machine $(f=52.5 \mathrm{~Hz})$ and an ER machine $(f=120 \mathrm{~Hz})$. The stress ratio for all tests is -1 .

Figure 2A shows the hour-glass shaped specimen used in RB machine, for which the minimum diameter is $4 \mathrm{~mm}$ and the round notch radius is $7 \mathrm{~mm}$. The specimen used in ER machine (Figure 2B) is also hour-glass type with the minimum diameter of $3 \mathrm{~mm}$ and the round notch radius of $31 \mathrm{~mm}$, for which a button head was designed at both ends to ensure the clamping by the fixture of the ER machine. Figure $2 \mathrm{C}$ shows the assembly drawing of ER specimen, in

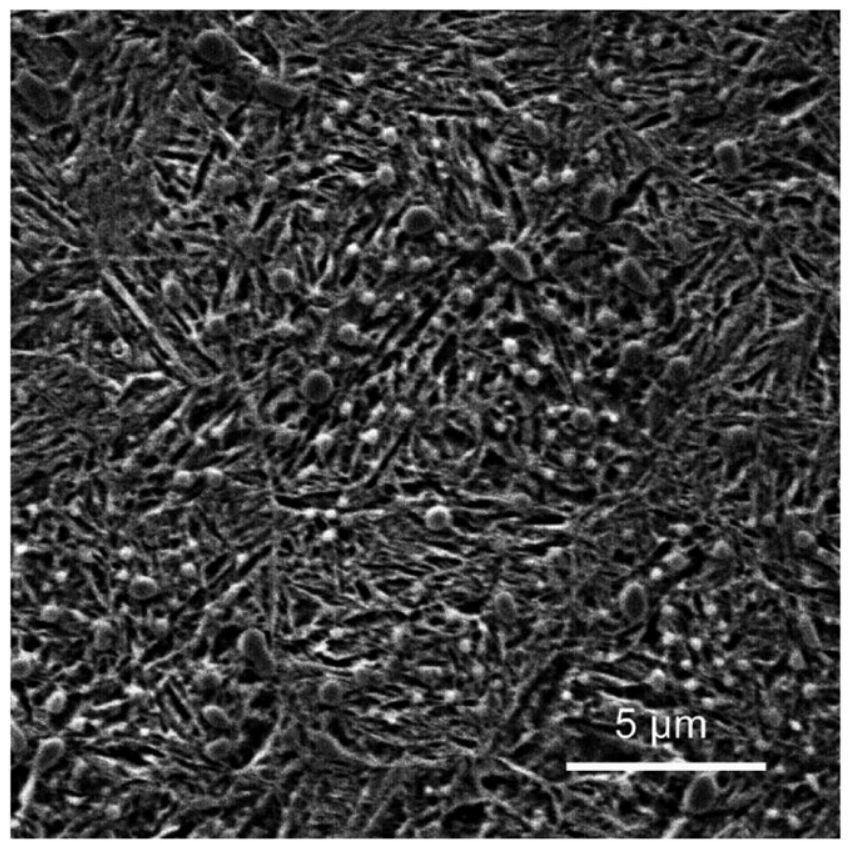

FIGURE 1 SEM image showing the microstructure (tempered martensite with carbides) of test material 
which the ER specimen was clamped by upper and lower fixture, and each fixture was fixed by 6 screws with the upper and the lower crosshead. Before fatigue testing, the round notch surface of every specimen was polished by using abrasive papers with grade $400,800,1500$, and 2000 to eliminate machining scratches.

For the testing of VA cycling or repeated 2-step loading in RB machine, an electromagnetic control device as shown in Figure 3A was developed for the purpose of automatically alternating the low and high load condition. A timer capable of power on and off is connected with an electromagnet. When the timer is power on, the electromagnet pulls up the miniweights from the lifting platform, and the specimen is under high stress loading condition. On the contrary, when the timer is power off, the miniweights falls off from the electromagnet, and the specimen is under low stress loading condition.

For the testing of VA cycling or repeated 2-step loading in ER machine, the change of loading was automatically controlled by the machine.

As shown in Figure 3B, during the VA cycling, the high stress amplitude with $n_{\mathrm{H}}$ cycles and the low stress amplitude with $n_{\mathrm{L}}$ cycles were applied alternately until the failure of the specimen. Every test of VA cycling began with the loading of low stress amplitude followed by high stress amplitude, and a section of $n_{\mathrm{L}}$ plus $n_{\mathrm{H}}$ was defined as 1 loading block. Different combinations of high stress and low stress were arranged with reference to the $\mathrm{CA}$ cycling test results. Table A1 in Appendix lists the test parameters for all specimens (20 specimens by RB method and 4 specimens by ER method) tested via VA cycling, ie, repeated 2-step loading.

\section{3 | Fracture surface observation}

The fracture surfaces of all failed specimens were cleaned by an ultrasonic cleaner containing anhydrous ethanol and then observed by using a field-emission type SEM. The observation was focused on the region of crack initiation and early growth. For the observation of the microstructure underneath crack initiation region, profile samples with the size of $10 \mu \mathrm{m}$ (width) $\times 5 \mu \mathrm{m}$ (depth) $\times 60 \mathrm{~nm}$ (thickness) were cut by FIB technique with a Hellos Nanolab 600i device. Before the cutting, a Pt protection layer was coated on the target location to protect the surface of initiation region from damage. The prepared profile samples were carefully examined via a TEM equipped with an SAD unit with the diffraction area of $280 \mathrm{~nm}$ in diameter. The obtained SAD patterns were calibrated and indexed.

\section{3 | EXPERIMENTAL RESULTS AND DISCUSSION}

\section{1 | S-N data}

Figure 4A shows the results of S-N data under CA cycling via both $\mathrm{RB}$ and $\mathrm{ER}$ method, indicating that the fatigue strength decreases with the increase of loading cycles. The crack initiation of most specimens failed in $\mathrm{HCF}$ regime $\left(5 \times 10^{5}-1 \times 10^{7}\right.$ cycles $)$ was from the interior of specimen, and all the fatigue failures originated from the interior of specimen in the VHCF regime (beyond $10^{7}$ cycles). Figure $4 \mathrm{~A}$ also indicates that the fatigue strength by RB method has a trend of duplex pattern and is 50 to $100 \mathrm{MPa}$ higher than that by ER method for the interior crack initiation mode at fatigue life above $10^{6}$ cycles, which may be ascribed to the effect of loading
(A)

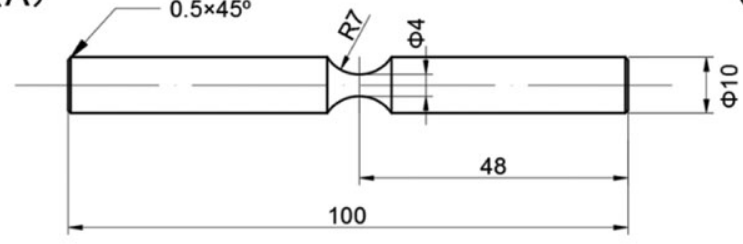

(B)

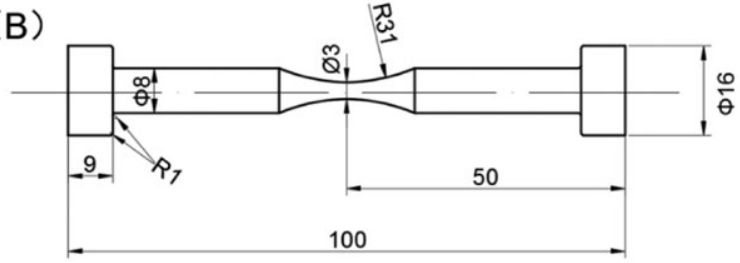

(C)

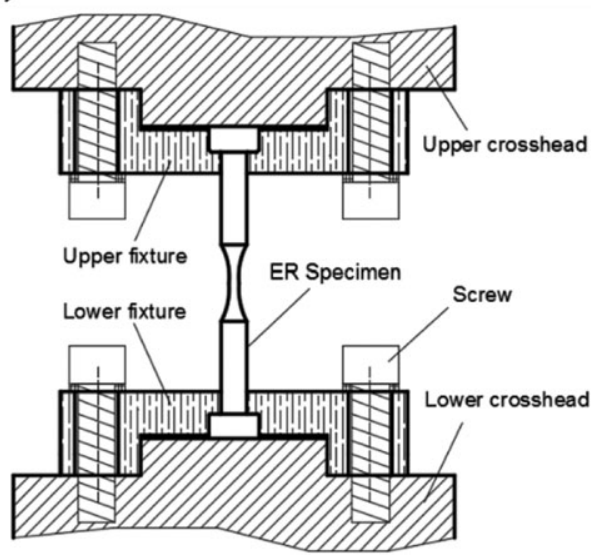

FIGURE 2 Shape and dimensions ( $\mathrm{mm}$ ) of fatigue test specimens: A, used in RB machine; B, used in ER machine; C, assembly drawing of ER specimen 

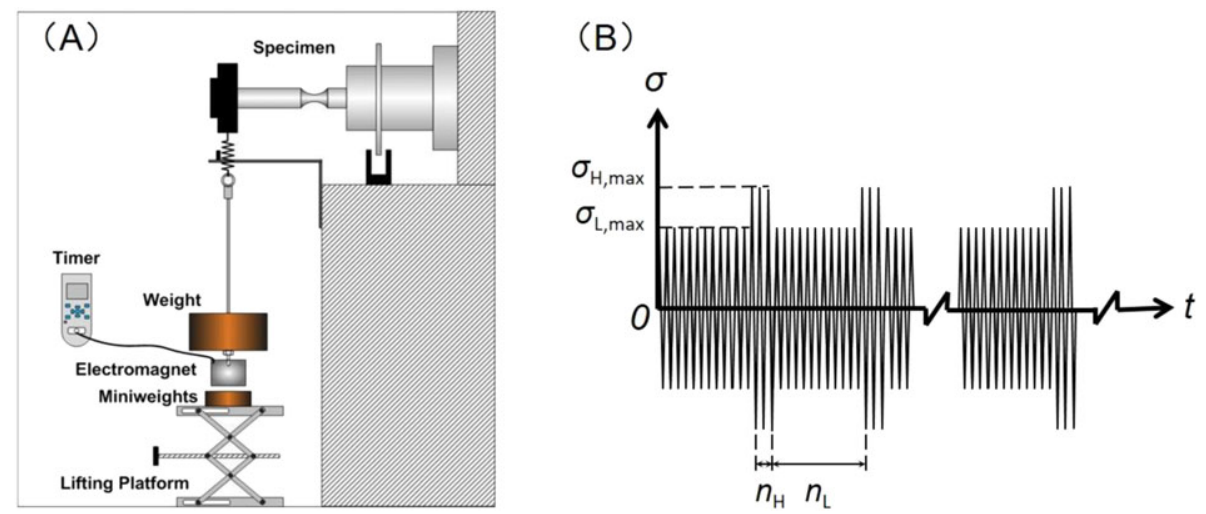

FIGURE 3 A, Schematic of control device for VA cycling in RB machine; B, schematic of repeated 2-step loading scheme [Colour figure can be viewed at wileyonlinelibrary.com]

method: stress gradient feature on the cross section for $\mathrm{RB}$ method versus the stress uniform distribution on the cross section for ER method. In other words, the control volume under RB loading $\left(5.63 \mathrm{~mm}^{3}\right)$ is evidently smaller than that under ER axial cycling $\left(32.6 \mathrm{~mm}^{3}\right)$. Thus, ER method has higher risky possibility than RB method, which leads to the fatigue strength by ER method is lower than that by RB method. The specimen size effect on fatigue life in the light of control volume concept has been comprehensively investigated in our previous papers. $^{39,40}$

The fatigue test data of VA cycling are characterized by the cumulative damage $D_{\mathrm{f}}$, which is based on Miner cumulative damage theory ${ }^{41}$ and is written as, ${ }^{35}$

$$
D_{\mathrm{f}}=D_{\mathrm{H}}+D_{\mathrm{L}}=\sum \frac{n_{\mathrm{H}}}{N_{\mathrm{Hf}}}+\sum \frac{n_{\mathrm{L}}}{N_{\mathrm{Lf}}}
$$

where $D_{\mathrm{H}}$ is the cumulative damage under high stress, $D_{\mathrm{L}}$ is the cumulative damage under low stress, and $N_{\mathrm{Hf}}$ and $N_{\mathrm{Lf}}$ are the median fatigue lives corresponding to high stress and low stress conditions under CA cycling, respectively.

Figure 4B shows the values of cumulative damage $\left(D_{\mathrm{H}}\right.$ and $\left.D_{\mathrm{L}}\right)$ as a function of applied maximum stress for high stress and low stress under VA cycling with RB and ER method. It is seen that under the present 2-step cycling condition, the values of $D_{\mathrm{H}}$ are slightly higher than those of $D_{\mathrm{L}}$, and the values of total cumulative damage $\left(D_{\mathrm{f}}\right)$ are close to those of $D_{\mathrm{H}}$ (Figure $4 \mathrm{C}$ ), which implies that the cumulative damage resulted from high stress component is more substantial than that from low stress component, or the high stress cycling plays a dominant role in the fatigue failure process. It should be mentioned that the relation between $D_{\mathrm{H}}$ and $D_{\mathrm{L}}$ as well as each component with respect to $D_{\mathrm{f}}$ is dependent on the difference of the related high stress and low stress and on the ratio of loading cycles between the 2 components. It is also noticed that the values of $D_{\mathrm{f}}$ (Figure $4 \mathrm{C}$ ) distribute between 0.2 and 5, suggesting a large scattering of fatigue life for the test material, which is the propensity of metallic materials.

\section{2 | Crack propagation rates in initiation region}

SEM observations of the fractography for all failed specimens were carried out, and crack growth traces in the initiation region were carefully searched for the specimens under VA cycling with RB method. It is a challenge that the evidence of crack propagation in the initiation region for VHCF is not easy to be found. This is due to 2 folds: the first is that the width of crack growth traces is quite small in relation to the very small crack growth rate, and the second is that the fracture surface is quite rough in the latter part of the FGA region where the traces may be located. The small width trace mixed with the rough surface makes the appearance of the trace hardly to be identified. Nevertheless, based on the efforts of selecting the appropriate combination of low stress and high stress in VA cycling and using the appropriate magnification in the imaging process, the crack propagation traces in the initiation region for several specimens under VA cycling have been successfully found.

As shown in Figures 5 and 6 for the specimens RB-6 and RB-15 failed in VHCF regime, the crack growth traces of specimen RB-6 in Figure 5 are clearer than those of specimen RB-15 in Figure 6, which may be the result of more loading blocks (720 blocks) for specimen RB- 6 than those for RB-15 (65 blocks). Figures 5B, C and 6B show the enlargement of crack growth traces in Figures $5 \mathrm{~A}$ and $6 \mathrm{~A}$, respectively. In Figures 5B, C and 6B, the crack growth traces caused by VA cycling are marked by double arrow bars. The widths of crack growth traces are in the 
(A)

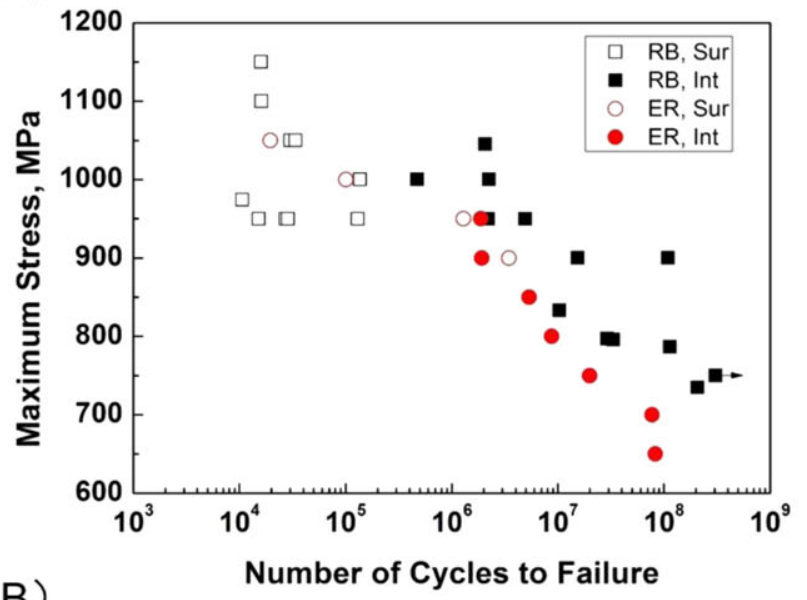

(B)

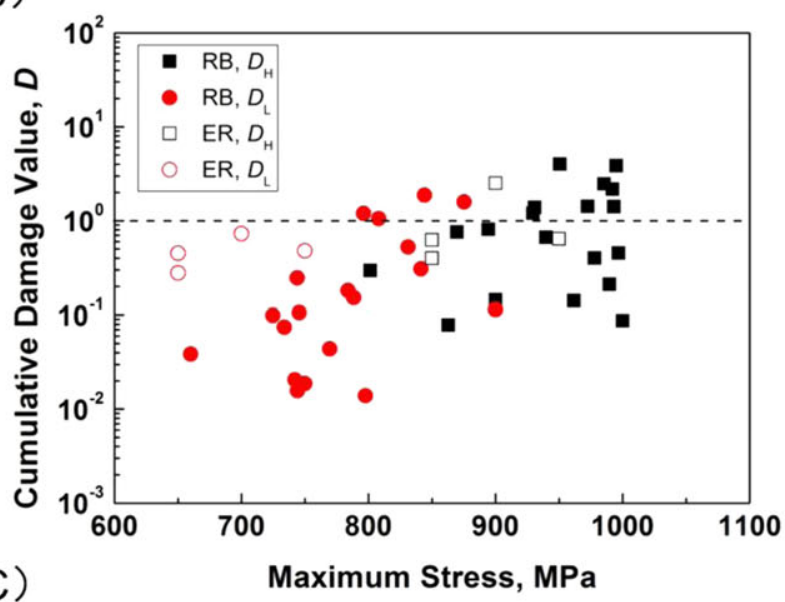

(C)

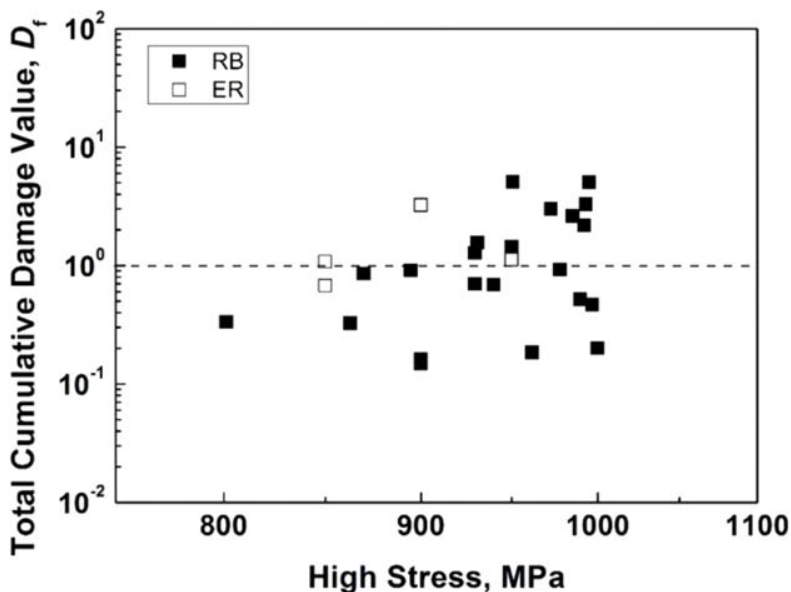

FIGURE 4 A, S-N data under CA cycling, Sur: Crack surface initiation, Int: Crack interior initiation; B, cumulative damage value for high stress and low stress under VA cycling with $\mathrm{RB}$ and ER method; $\mathrm{C}$, total cumulative damage value versus high stress under VA cycling with RB and ER method [Colour figure can be viewed at wileyonlinelibrary.com]

range between 1 and $5 \mu \mathrm{m}$ in Figure 5, and between 0.5 and $2 \mu \mathrm{m}$ in Figure 6. It is noticed from Figures 5 and 6 that the location of the captured crack growth traces is in the latter part of FGA region.
The captured traces in crack initiation region are the direct evidence of crack growth in FGA, and it is judged that a section of trace width is caused by 1 loading block. Then, the crack growth rates in FGA were readily calculated via the width of traces divided by the cycles of 1 loading block, ie, $\Delta a /\left(n_{\mathrm{L}}+n_{\mathrm{H}}\right)$. The results of crack growth rates in FGA are shown in Figure 7A, presenting 3 datum groups with $n_{\mathrm{L}}$ as $1 \times 10^{4}, 1 \times 10^{5}$, and $2 \times 10^{6}$. Note that the cycles of 1 loading block are mainly dependent on $n_{\mathrm{L}}$ which is 10 to 100 times as much as $n_{\mathrm{H}}$. It is seen that the crack growth rates in FGA are in the range between $5.4 \times 10^{-11}$ and $9.4 \times 10^{-11} \mathrm{~m} /$ cycle (average $7.2 \times 10^{-11} \mathrm{~m} /$ cycle) for $n_{\mathrm{L}}=1 \times 10^{4}$ (blue triangle symbols in Figure 7A), between $4.3 \times 10^{-12}$ and $3.3 \times 10^{-11} \mathrm{~m} /$ cycle (average $1.2 \times 10^{-11} \mathrm{~m} /$ cycle) for $n_{\mathrm{L}}=1 \times 10^{5}$ (pink inverted triangle symbols in Figure 7A), and between $2.7 \times 10^{-13}$ and $7.7 \times 10^{-13} \mathrm{~m} /$ cycle (average $4.8 \times 10^{-13} \mathrm{~m} /$ cycle) for $n_{\mathrm{L}}=2 \times 10^{6}$ (green diamond symbols in Figure 7A), respectively, with the corresponding $\Delta K$ values in the range of $4 \sim 6 \mathrm{MPa} \cdot \mathrm{m}^{1 / 2}$. Here, the $\Delta K$ values were calculated by Equation 2, that is

$$
\Delta K=0.5 \Delta \sigma_{\mathrm{a}} \sqrt{\pi \sqrt{\text { area }}}
$$

with $\Delta \sigma_{\mathrm{a}}$ being the stress amplitude for $R=-1$, and area the projection area of the crack. Equation 2 was proposed by Murakami et $\mathrm{al}^{42}$ to estimate the values of SIF for interior cracks and was commonly used in the fatigue damage cases with regard to inclusions, FGAs and FiEs. In Equation 2, the parameter $0.5 \sqrt{\pi}$ represents the crack shape correction factor for an interior crack, and $\sqrt{\text { area }}$ represents the equivalent crack length. For the case of crack growth traces, $r \sqrt{\pi}$ was used to replace $\sqrt{\text { area }}$ in the calculation, where $r$ is the distance from the center of crack origin (ie, inclusion center) to the middle point of the related trace and the high stress component in VA cycling was used in the calculation.

Researchers such as Ogawa et $\mathrm{al}^{35}$ and Sander et $\mathrm{al}^{37,38}$ have made special efforts to obtain the crack growth rates in the initiation process of VHCF. Both of these groups used VA cycling approach to show the beach marks $^{35}$ or arrest marks ${ }^{37,38}$ in the FiE region (outside FGA) and the crack growth rates were estimated, but no crack growth traces in FGA region were detected. For the comparison with the present data in FGA, the crack growth rates from beach marks ${ }^{35}$ or arrest marks ${ }^{37,38}$ in FiE are also plotted in Figure 7A. It is seen that the crack growth rates in FiE by Ogawa et $\mathrm{al}^{35}$ (red circular symbols in Figure 7A) are higher than that by Sander et $\mathrm{al}^{38}$ (black square symbols in Figure 7A), which is probably due to the different values of $n_{\mathrm{L}}$. For the data of $10^{-9}$ to $10^{-7} \mathrm{~m} /$ cycle by Ogawa et al, ${ }^{35} n_{\mathrm{L}}$ is $1 \times 10^{4}$ and for the 


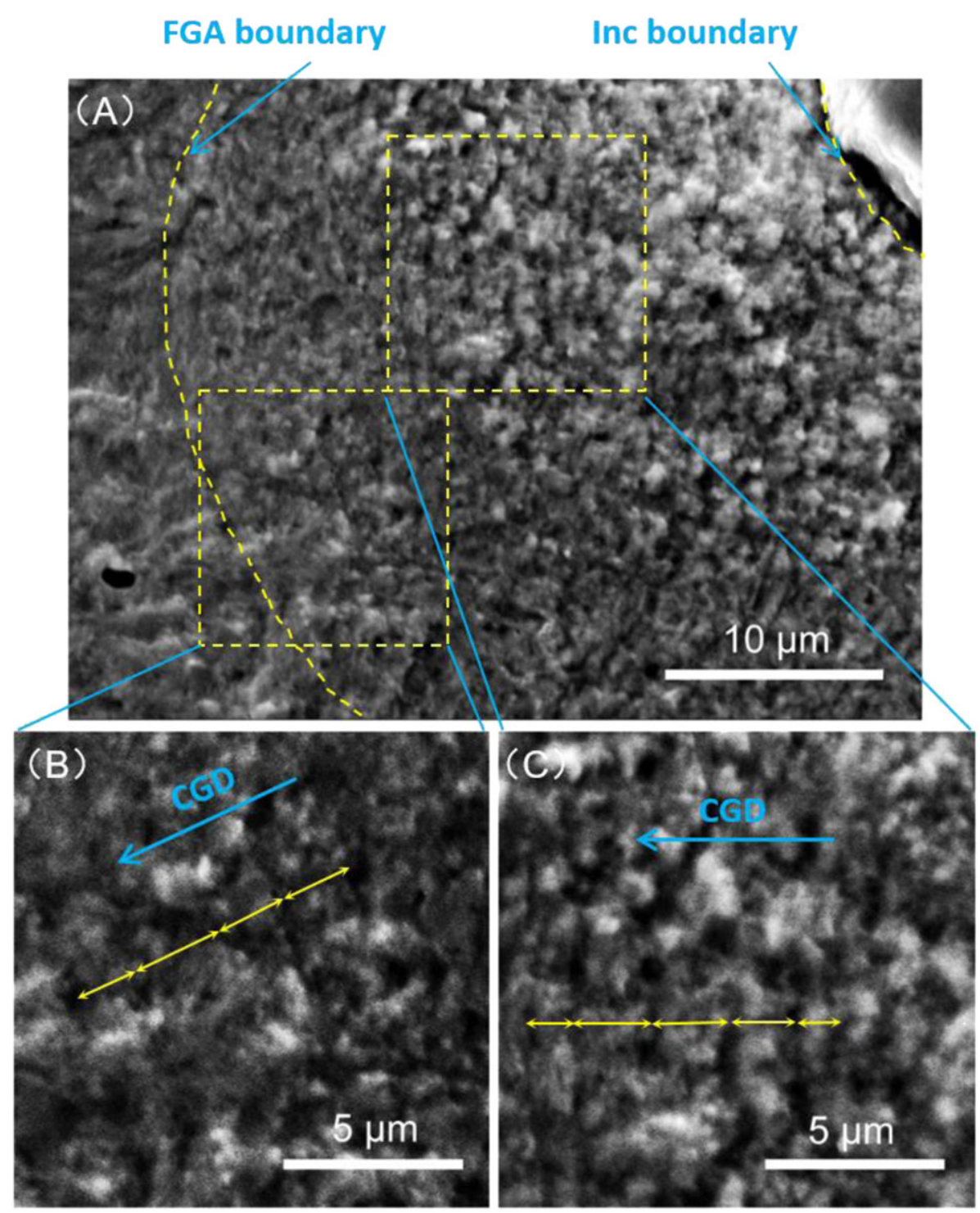

FIGURE 5 SEM photos for specimen RB-6 under VA cycling with RB method, CGD: Crack growth direction $\left(\sigma_{\mathrm{H}, \max }=1000 \mathrm{MPa}, \sigma_{\mathrm{L}}, \max \right.$ $\left.=850 \mathrm{MPa}, N_{\mathrm{f}}=7.2 \times 10^{7}, n_{\mathrm{H}}=5 \times 10^{3}, n_{\mathrm{L}}=1 \times 10^{5}, R=-1\right)$ : A, crack growth traces in FGA region; B, C, enlargement of crack growth traces in $\mathrm{A}$, and double arrow bar indicating trace width [Colour figure can be viewed at wileyonlinelibrary.com]

data of $10^{-12}$ to $10^{-10} \mathrm{~m} /$ cycle by Sander et $\mathrm{al}^{38} n_{\mathrm{L}}$ is $2.3 \times 10^{6}$. It is interesting to see a good linear trend from the present results of crack growth rates in FGA to the data in FiE under the same value of $n_{\mathrm{L}}$, which reflects the evolution of crack growth rates from FGA to FiE region.

For a verification of the crack growth rates obtained by the captured traces in FGA region, the equivalent crack growth rates were calculated for the specimens failed with FGA pattern on fracture surface. Equivalent crack growth rate is defined as the radius of FGA divided by the total fatigue life, which is based on the fact that the FGA region consumes more than $95 \%$ of the total fatigue life. ${ }^{17}$ The values of equivalent crack growth rates of FGA are plotted in Figure 7B. In fact, the crack growth rate is increasing from the boundary of the inclusion to the boundary of the FGA due to the extension of crack size. Hence, the crack growth rates from the captured traces locating at the latter part of the FGA region are necessarily larger than the equivalent crack growth rates (average values) of the FGA. Figure 7B shows that the equivalent crack rates are in the range between $10^{-14}$ and $10^{-11} \mathrm{~m} /$ cycle, which are within the same range but relatively smaller than those calculated by the captured traces in FGA region shown in Figure 7A. Especially, the equivalent crack rates of the 3 specimens with crack growth traces are $4.5 \times 10^{-13} \mathrm{~m} /$ cycle (blue circular symbol in Figure 7B) for $n_{\mathrm{L}}=1 \times 10^{4}, 2.6 \times 10^{-13} \mathrm{~m} /$ cycle (pink circular symbol in Figure $7 \mathrm{~B}$ ) for $n_{\mathrm{L}}=1 \times 10^{5}$ and $1.2 \times 10^{-13} \mathrm{~m} /$ cycle (green circular symbol in Figure 7B) 


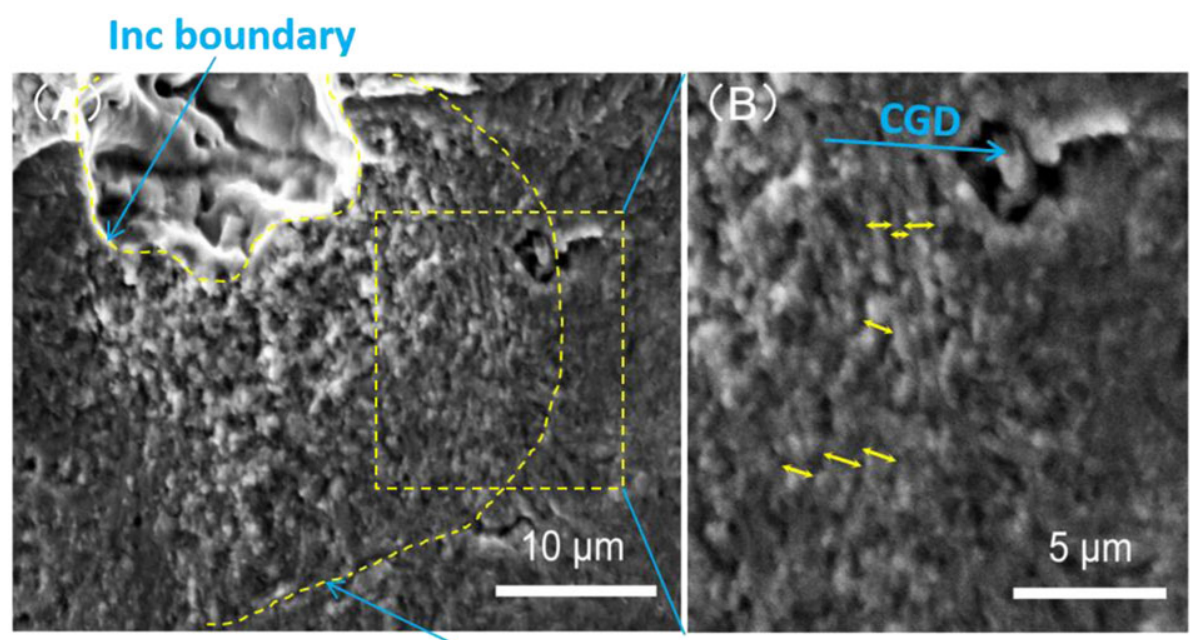

FGA boundary

FIGURE 6 SEM photos for specimen RB-15 under VA cycling with RB method, CGD: Crack growth direction $\left(\sigma_{\mathrm{H}, \max }=900 \mathrm{MPa}, \sigma_{\mathrm{L}, \max }=\right.$ $\left.750 \mathrm{MPa}, N_{\mathrm{f}}=1.3 \times 10^{8}, n_{\mathrm{H}}=2 \times 10^{5}, n_{\mathrm{L}}=2 \times 10^{6}, R=-1\right)$ : A, crack growth traces in FGA region; B, enlargement of crack growth traces in $\mathrm{A}$, and double arrow bar indicating trace width [Colour figure can be viewed at wileyonlinelibrary.com]
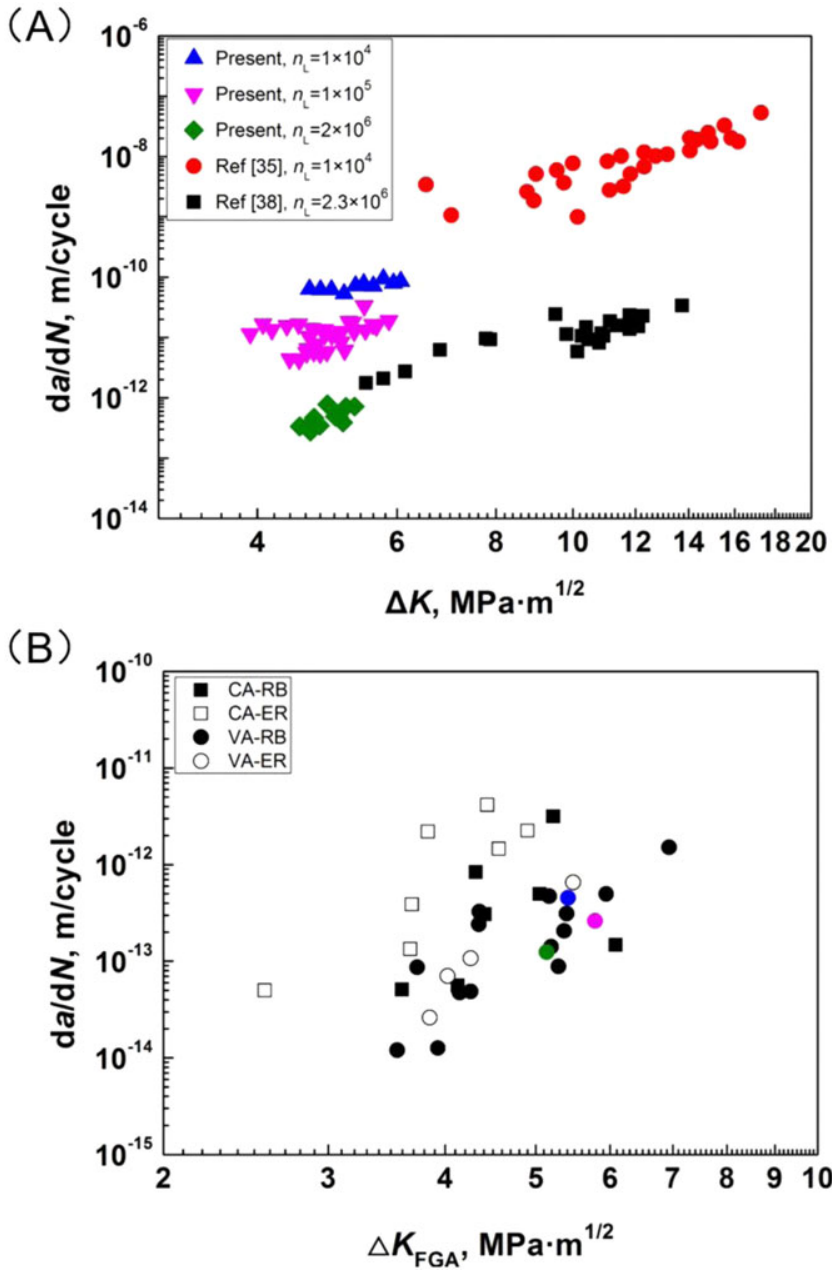

FIGURE 7 A, results of crack growth rates in initiation region of present investigation and from refs $^{35,38}$; B, equivalent crack growth rates of FGA under CA and VA cycling with RB and ER method [Colour figure can be viewed at wileyonlinelibrary.com] for $n_{\mathrm{L}}=2 \times 10^{6}$, which are below the related measured data from crack growth traces shown in Figure 7A. Thus, it is suggested that the obtained crack growth rates in the FGA region by the captured traces are reasonable and convincible.

Figure 7B also shows that the equivalent crack growth rates under VA cycling (circular symbols in Figure 7B) are slower than those under CA cycling (square symbols in Figure $7 \mathrm{~B}$ ). In addition, the equivalent crack growth rates with $\mathrm{RB}$ method (solid symbols in Figure $7 \mathrm{~B}$ ) are slower than those with ER method (hollow symbols in Figure 7B) under CA cycling. Note that the average size of the FGAs as well as the inclusions is very close for all loading conditions (results and discussion in Section 3.4), so the difference of equivalent crack growth rates between different conditions is mainly caused by the related total fatigue life. Although the equivalent crack growth rates are different for VA versus CA cycling, more caution should be taken to make the fatigue life comparison between these 2 cases just based on the equivalent crack growth rates in the FGA region.

\section{3 | Fracture surface morphology and profile feature}

The observation via SEM on the failed specimens under $\mathrm{CA}$ and VA cycling indicated that crack initiation was all from the interior of specimen in VHCF regime, and the crack initiation was from an inclusion except 1 under CA cycling by RB method originated from grain boundary.

Figure 8 shows the typical fracture surface morphology of 3 specimens failed from the interior of specimens under CA and VA cycling with RB and ER 

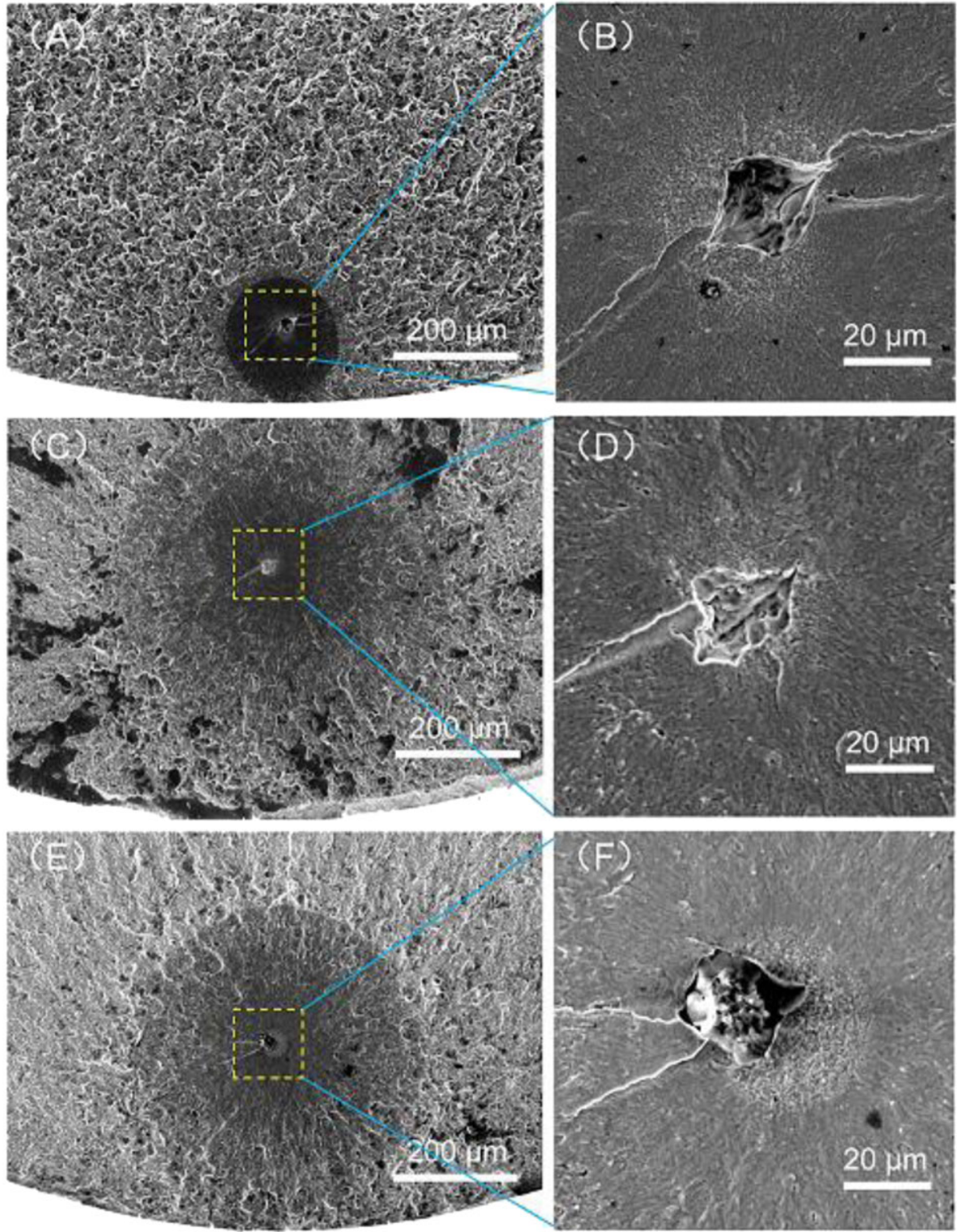

FIGURE 8 SEM photos showing crack initiation morphology under CA and VA cycling with RB and ER method: A, crack initiation region for a specimen subjected to $\mathrm{CA}$ cycling with $\mathrm{RB}$ method $\left(\sigma_{\max }=850 \mathrm{MPa}, N_{\mathrm{f}}=3.3 \times 10^{7}, R=-1\right)$; B, high magnification of crack origin in A; C, crack initiation region for a specimen subjected to CA cycling with ER method $\left(\sigma_{\max }=850 \mathrm{MPa}, N_{\mathrm{f}}=5.4 \times 10^{6}, R=-1\right)$; , high magnification of crack origin in $\mathrm{C}$; E, crack initiation region for a specimen subjected to VA cycling with ER method $\left(\sigma_{\mathrm{H}, \max }=950 \mathrm{MPa}\right.$, $\sigma_{\mathrm{L}, \max }=750 \mathrm{MPa}, N_{\mathrm{f}}=1.6 \times 10^{7}, n_{\mathrm{H}}=1 \times 10^{4}, n_{\mathrm{L}}=5 \times 10^{5}, R=-1$ ); F, high magnification of crack origin in $\mathrm{E}$ [Colour figure can be viewed at wileyonlinelibrary.com]

method in the VHCF regime, in which the FiE contains an FGA surrounding an inclusion as crack origin. Figure 8A was taken of a specimen failed in VHCF under CA cycling with RB method, showing a clear FiE (tangent to the surface of specimen) of approximately $200 \mu \mathrm{m}$ in diameter. The enlargement (Figure $8 \mathrm{~B}$ ) of the initiation region shows an FGA region surrounding the initiation site due to an inclusion of approximately $20 \mu \mathrm{m}$ in diameter. Figure $8 \mathrm{C}$ and $\mathrm{E}$ was taken of specimens failed in VHCF with ER method with the former under CA cycling and the latter under VA cycling. Both images show clear FiE morphology with the diameter of approximately $500 \mu \mathrm{m}$. The high magnification images (Figure $8 \mathrm{D}$ and $\mathrm{F}$ ) of the crack initiation region show that the crack initiates from an inclusion surrounded by an FGA region, and the size of inclusion is similar to the case with RB method (Figure 8B).

For the purpose of revealing the microstructure characteristics in the crack initiation region under VA cycling, profile samples were cut from the crack initiation sites of 3 specimens (RB-6, RB-15, and ER-3) via FIB method. For specimen RB-6 with clear crack growth traces in FGA, 1 sample (double arrow bars in Figure 9A) was cut in the location with clear crack growth traces. For 

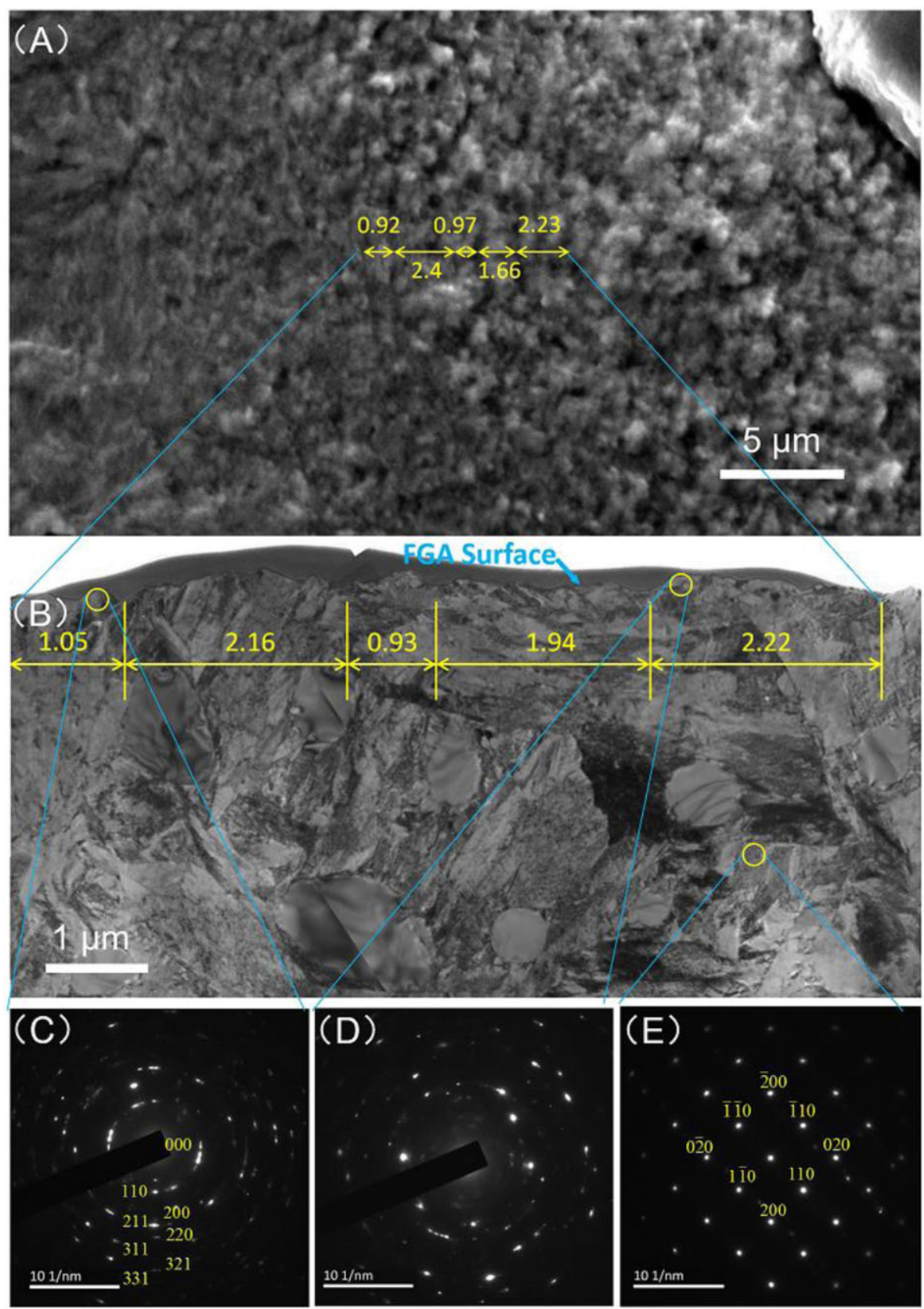

FIGURE 9 Detailed morphology of crack initiation region for specimen RB-6 under VA cycling with RB method $\left(\sigma_{\mathrm{H}, \max }=1000 \mathrm{MPa}, \sigma_{\mathrm{L}}\right.$, $\left.\max =850 \mathrm{MPa}, N_{\mathrm{f}}=7.2 \times 10^{7}, n_{\mathrm{H}}=5 \times 10^{3}, n_{\mathrm{L}}=1 \times 10^{5}, R=-1\right)$ : A, SEM image of fracture surface, the total length of 5 double arrow bars being TEM sample location; B, TEM image of microstructure feature underneath FGA region showing "hills" and "valleys" (with width value in $\mu \mathrm{m}$ ) on fracture surface matching with relevant part in A; C, D, discontinuous diffraction circles of SAD at the location just underneath FGA surface; E, SAD pattern of isolated spots at the matrix [Colour figure can be viewed at wileyonlinelibrary.com]

specimens RB-15 (with clear crack growth traces in FGA) and ER-3 (without crack growth traces in FGA), 1 sample for each specimen (dashed rectangle in Figures 10A and 11A) was cut in the FGA region, and the cutting position does not contain evident crack growth traces.

In the TEM image of Figure 9B, it is seen the "hills" and "valleys" on the fracture surface and the relevant widths are marked with double arrow bars with the measured width values, which almost match with the relevant parts of the crack growth traces from the top view of FGA surface in Figure 9A. Figures 9C, D, and E are the examples of SAD detections, with Figures $9 \mathrm{C}$ and $\mathrm{D}$ being from the locations just underneath the fracture surface and Figure 9E away from the fracture surface. The SAD patterns of discontinuous diffraction circles (Figure 9C and D) indicate several grains within the diffraction area of $280 \mathrm{~nm}$ in diameter, namely a nanograin layer underneath the FGA surface. Whereas 

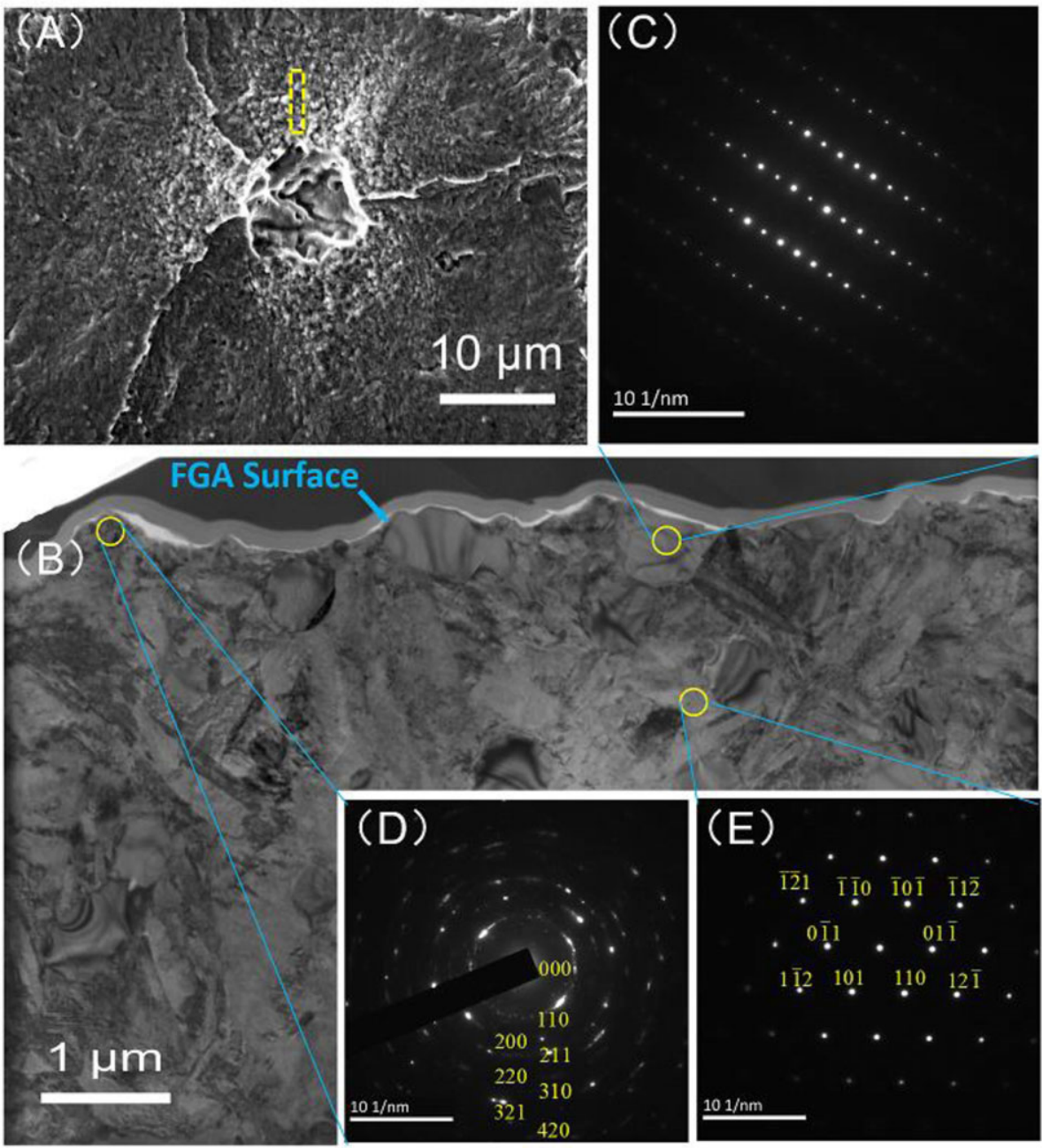

FIGURE 10 Detailed morphology of crack initiation region for specimen RB-15 under VA cycling with RB method $\left(\sigma_{\mathrm{H}, \max }=900 \mathrm{MPa}, \sigma_{\mathrm{L}}\right.$, $\left.\max =750 \mathrm{MPa}, N_{\mathrm{f}}=1.31 \times 10^{8}, n_{\mathrm{H}}=2 \times 10^{5}, n_{\mathrm{L}}=2 \times 10^{6}, R=-1\right)$ : A, SEM image of fracture surface, dashed rectangle being TEM sample location; B, TEM image of microstructure feature underneath FGA region; C, SAD pattern of a fractured carbide just underneath FGA surface; D, discontinuous diffraction circles of SAD at the location just underneath FGA surface; E, SAD pattern of isolated spots at the matrix [Colour figure can be viewed at wileyonlinelibrary.com]

the SAD pattern of isolated spots (Figure 9E) indicates just a single grain in the diffraction area at the location away from the FGA surface.

Figures 10 and 11 are SEM images, TEM images, and SAD patterns for specimens RB-15 and ER-3, respectively. The profile samples (dashed rectangle in Figures 10A and $11 \mathrm{~A}$ ) are from the locations close to the crack origin allowable for the examination of the microstructure detail in the FGA region. In addition to tempered martensites, several fractured carbides are observed in the FGA surface layer in Figure 10B, and the SAD pattern (Figure 10C) displays isolated spots meaning that the fractured carbide is not refined for the reason of its high strength. Figures 10D, $11 \mathrm{C}$, and $11 \mathrm{D}$ of the SAD detections indicate that the microstructure just underneath the FGA surface (related circles in Figure $10 \mathrm{~B}$ and $11 \mathrm{~B}$ ) is a nanograin layer. Whereas Figures 10E and 11E of the SAD detections show the isolated spots, suggesting just 1 grain in the diffraction area at the location away from the fracture surface (remaining coarse grain microstructure).

The above results of SAD patterns (Figures 9-11) definitely reveal that FGA region is a nanograin layer under VA cycling with both RB and ER method, just like the situation under CA cycling. ${ }^{24}$ The above results from the testing via VA cycling (Figures 9-11) are the new evidences to support the conclusion that FGA is a nanograin layer caused by NCP process. ${ }^{24,26}$

\section{4 | Values of SIF range for inclusions and FGAs}

The areas of the inclusions (as crack origin) and the surrounded FGAs were measured for all failed specimens, and their square root values, ie, the average size of the inclusions and the FGAs, were calculated. Table 1 lists the average values of the inclusions and the FGAs for 

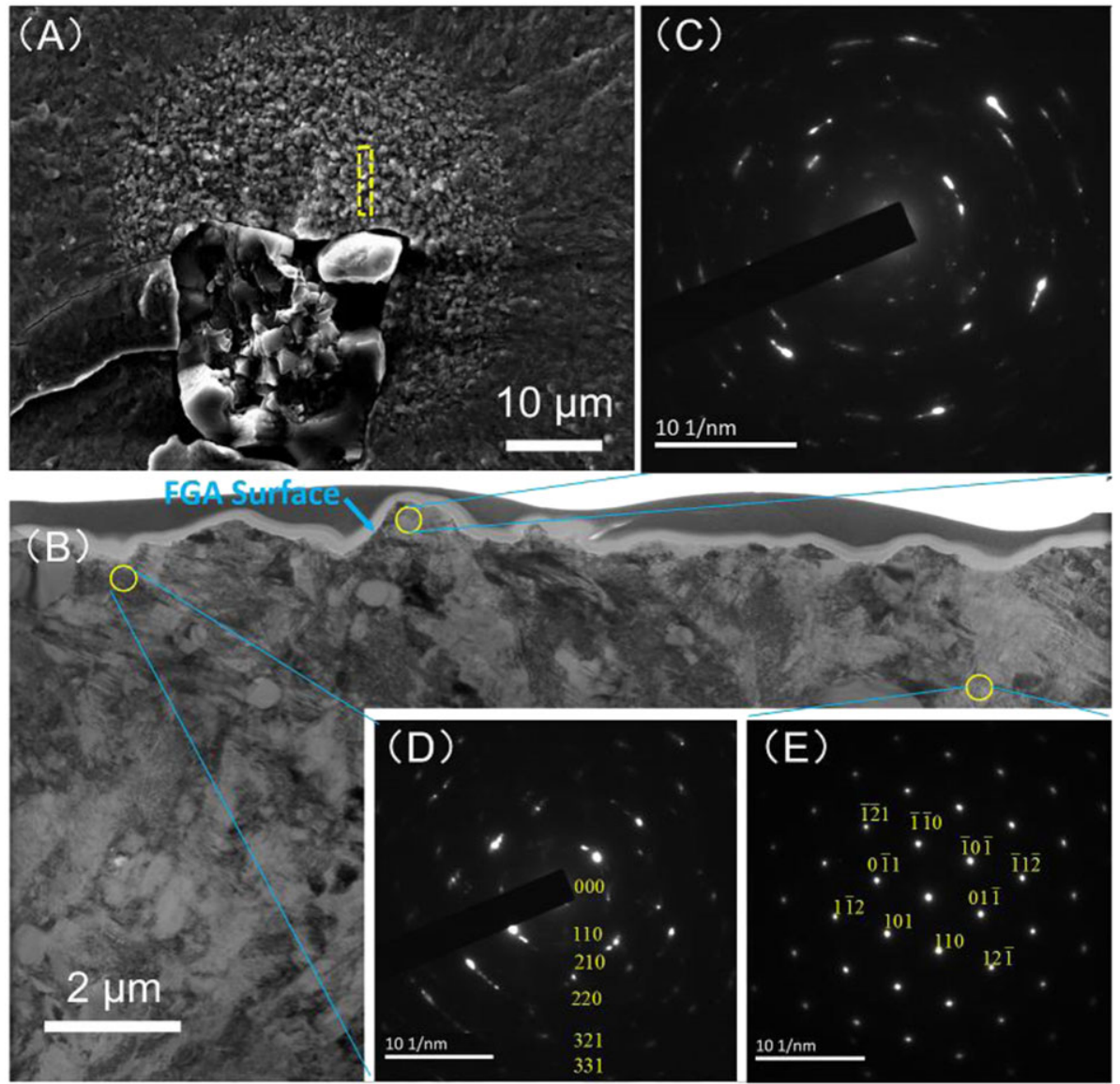

FIGURE 11 Detailed morphology of crack initiation region for specimen ER-3 under VA cycling with ER method $\left(\sigma_{\mathrm{H}, \max }=950 \mathrm{MPa}, \sigma_{\mathrm{L}}\right.$, $\left.\max =750 \mathrm{MPa}, N_{\mathrm{f}}=1.6 \times 10^{7}, n_{\mathrm{H}}=1 \times 10^{4}, n_{\mathrm{L}}=5 \times 10^{5}, R=-1\right)$ : A, SEM image of fracture surface, dashed rectangle being TEM sample location; B, TEM image of microstructure feature underneath FGA region; C, D, discontinuous diffraction circles of SAD at the location just underneath FGA surface; E, SAD pattern of isolated spots at the matrix [Colour figure can be viewed at wileyonlinelibrary.com]

TABLE 1 Average values of $\sqrt{\text { area }}$ and $\Delta K$ for the inclusions (as crack origins) and the surrounded FGAs of specimens under CA and VA cycling with RB and ER method

\begin{tabular}{lllll} 
& \multicolumn{4}{l}{$\sqrt{\text { area }}(\mu \mathrm{m}) / \Delta \boldsymbol{K}\left(\mathbf{M P a} \cdot \mathbf{m}^{\mathbf{1} / \mathbf{2}}\right)$} \\
\cline { 2 - 5 } & CA-RB & VA-RB & CA-ER & VA-ER \\
Inc & $19.4 / 3.60$ & $16.8 / 3.55$ & $16.4 / 3.03$ & $19.2 / 3.44$ \\
FGA & $36.7 / 4.69$ & $34.2 / 4.94$ & $31.6 / 3.95$ & $31.5 / 4.40$
\end{tabular}

the specimens under CA and VA cycling with RB and ER method, indicating that the average inclusion sizes for 4 loading conditions are within the range between 16.8 and $19.4 \mu \mathrm{m}$, and the average FGA sizes are within the range between 31.5 and $36.7 \mu \mathrm{m}$. It is clear that the control volume in the axial cycling by ER method $\left(32.6 \mathrm{~mm}^{3}\right)$ is substantially larger than that under RB method $\left(5.63 \mathrm{~mm}^{3}\right)$. This larger control volume will induce a higher possibility to find an inclusion with the size similar to that in RB method and to get the stress fluctuation required for crack initiation. Thus, the crack initiation in the ER case is likely to be earlier than that in the RB case.
Furtherly, the values of SIF range for inclusions and FGAs (regarded as interior cracks) were calculated by Equation 2. The values of SIF range for inclusions and FGAs are shown in Figure 12, and the relevant average values for 4 cyclic loading conditions are listed in Table 1. It is seen that the average values of SIF range for inclusions under CA and VA cycling are within a small range between 3.03 and $3.60 \mathrm{MPa} \cdot \mathrm{m}^{1 / 2}$, so are the average values of SIF range for FGAs ranging from 3.95 to $4.94 \mathrm{MPa} \cdot \mathrm{m}^{1 / 2}$.

The result in Table 1 also indicates that the average SIF value of FGA is close to the crack growth threshold value $\Delta K_{\text {th }}$ of the high-strength steel. ${ }^{43}$ It implies that when crack propagation is in the FGA region, the related $\Delta K$ value is below the traditional threshold of crack propagation. When the $\Delta K$ value is beyond the traditional threshold, FiE morphology will appear.

Here, the plastic zone size at crack tip $\left(r_{\mathrm{p}}\right)$ is introduced for the following discussion. For mode-I crack, $r_{\mathrm{p}}$ is ${ }^{44}$

$$
r_{\mathrm{p}}=\frac{(1-2 v)^{2}}{\pi}\left(\frac{\Delta K}{\sigma_{\mathrm{y}}}\right)^{2} \approx \frac{1}{6 \pi}\left(\frac{\Delta K}{\sigma_{\mathrm{y}}}\right)^{2}
$$



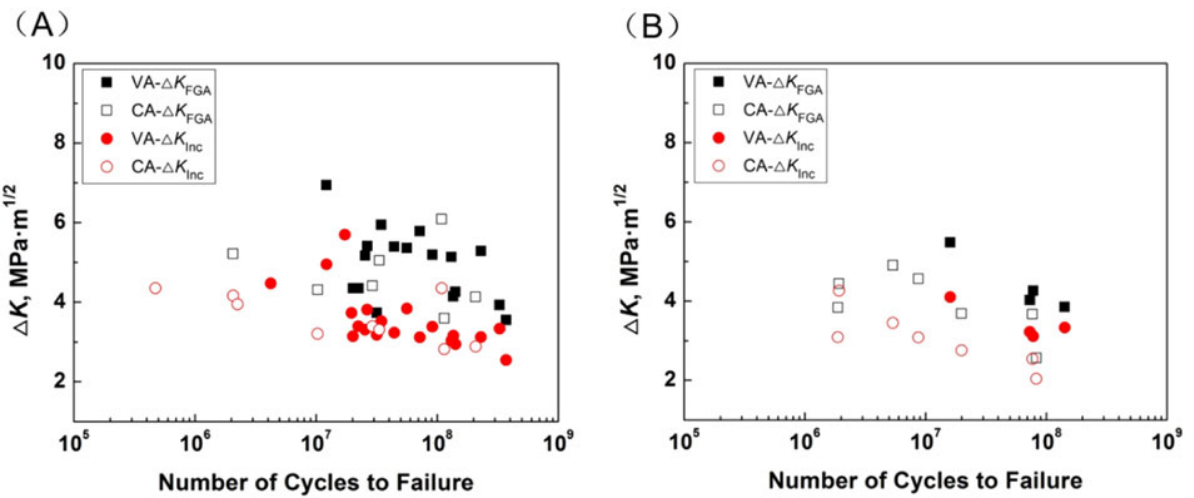

FIGURE 12 Values of SIF range for inclusions and FGAs: A, for RB method; B, for ER method [Colour figure can be viewed at wileyonlinelibrary.com]

where $v$ is Poisson ratio, $\Delta K$ is SIF range, and $\sigma_{\mathrm{y}}$ is yield stress of the given material. It is regarded that when the plastic zone size at crack tip equals to the characteristic dimension of related microstructure, the process of crack initiation, namely the formation of FGA, is terminated. ${ }^{45}$ For the present investigation, the plastic zone size at crack tip for FGA with RB method was calculated, and the average value is approximately $360 \mathrm{~nm}$ which is close to the previous results of martensite lamellar width $(378 \mathrm{~nm}) .{ }^{43,45}$ When the plastic zone size at crack tip within the FGA region is less than the width of martensite lamellar, the crack growth will be influenced by the microstructure. On the contrary, when the plastic zone size at crack tip is beyond the width of martensite lamellar, the crack growth will be less influenced by the microstructure and the surface morphology will be relatively smooth.

For the explanation of the appearance of crack growth traces in the initiation region, the FGA region of specimens RB-6 and RB- 15 were divided into 3 parts by yellow dashed curves, as shown in Figure 13. That is Part I: inclusion area, Part II: former part of FGA or early initiation region without crack growth traces, and
Part III: latter part of FGA or later initiation region with crack growth traces. The areas of the 3 parts were measured, and the associated plastic zone size at crack tip under high stress and low stress cycling were calculated by Equation 3, respectively. The results are listed in Table 2.

From Table 2, it is seen that in part I where the crack just initiated from the inclusion, the values of SIF range and plastic zone size for both specimens were relatively low for both high stress and low stress conditions. When the crack propagated to part II, the high stress cycling caused SIF range to a medium value (larger than $4 \mathrm{MPa} \cdot \mathrm{m}^{1 / 2}$ ) with the plastic zone size close to the width of martensite lamellar, and the low stress cycling resulted in a relatively low value of SIF range with a relatively small value of plastic zone size, for which the crack growth traces were unlikely to be produced. When the crack arrived at part III, the values of SIF range for high and low stress conditions were relatively large (above $4 \mathrm{MPa} \cdot \mathrm{m}^{1 / 2}$ ) and the values of plastic zone size under low and high stress conditions were close or larger than the width of martensite lamellar, for which crack growth traces were possibly produced.
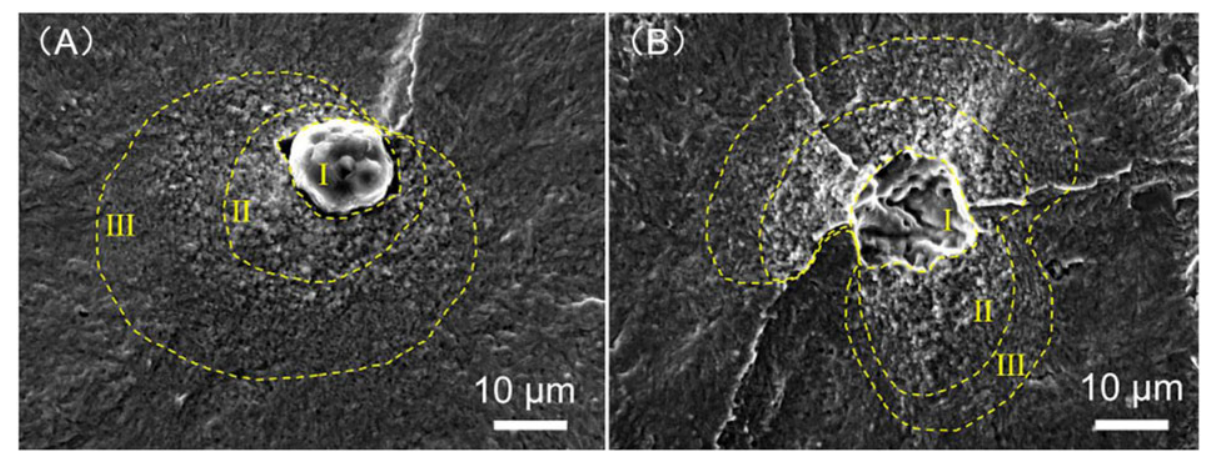

FIGURE 13 SEM images for specimens RB-6 and RB-15 with crack growth traces, the initiation region being divided into 3 parts by yellow dashed curves. A, SEM image for specimen RB-6 $\left(\sigma_{\mathrm{H}, \max }=1000 \mathrm{MPa}, \sigma_{\mathrm{L}, \max }=850 \mathrm{MPa}, N_{\mathrm{f}}=7.2 \times 10^{7}, n_{\mathrm{H}}=5 \times 10^{3}, n_{\mathrm{L}}=1 \times 10^{5}, R=-1\right)$; B, SEM image for specimen RB-15 $\left(\sigma_{\mathrm{H}, \max }=900 \mathrm{MPa}, \sigma_{\mathrm{L}, \max }=750 \mathrm{MPa}, N_{\mathrm{f}}=1.31 \times 10^{8}, n_{\mathrm{H}}=2 \times 10^{5}, n_{\mathrm{L}}=2 \times 10^{6}, R=-1\right)[$ Colour figure can be viewed at wileyonlinelibrary.com] 
TABLE 2 Values of SIF range and plastic zone size for 3 parts of FGA region for specimens RB-6 and RB-15 under high stress and low stress cycling

\begin{tabular}{|c|c|c|c|c|c|c|c|}
\hline & & \multicolumn{2}{|l|}{ Part I } & \multicolumn{2}{|l|}{ Part II } & \multicolumn{2}{|l|}{ Part III } \\
\hline \multirow[t]{2}{*}{ RB-6 } & $\Delta K\left(\mathrm{MPa} \cdot \mathrm{m}^{1 / 2}\right)$ & 2.81 & 3.34 & 3.73 & 4.38 & 4.82 & 5.76 \\
\hline & $r_{\mathrm{p}}(\mathrm{nm})$ & 128 & 178 & 224 & 303 & 377 & 532 \\
\hline \multirow[t]{2}{*}{ RB-15 } & $\Delta K\left(\mathrm{MPa} \cdot \mathrm{m}^{1 / 2}\right)$ & 2.60 & 3.12 & 3.74 & 4.49 & 4.46 & 5.35 \\
\hline & $r_{\mathrm{p}}(\mathrm{nm})$ & 111 & 160 & 229 & 329 & 326 & 469 \\
\hline
\end{tabular}

In addition, the appearance possibility of crack growth traces in VA cycling might be explained by the NCP concept. From Figure 13, it is obvious that the roughness of part II is more pronounced than part III for both specimens, which is resulted from more number of contacting between crack surfaces in the former part of the FGA, ie, part II experienced more loading cycles than part III. Such a process of large number of crack surface contacting with large roughness may eliminate the possible crack growth traces in part II. As a result, crack growth traces in part III (which is with less extent of roughness) are more likely to be visible. Certainly, the correctness of this hypothesis needs further investigations.

\section{4 | CONCLUSIONS}

In this paper, the crack growth rate and the microstructure feature of crack initiation region for a high-strength steel have been experimentally investigated and the conclusions are drawn as follows:

1. The S-N data of RB method under CA cycling have a trend of duplex pattern while those of ER method present a continuously decreasing shape. The fatigue strength of RB method is a little higher than that of ER method for the fatigue life above $10^{6}$ cycles.

2. It is the first time capturing the crack growth traces in the crack initiation region of FGA under VA cycling. The obtained crack growth rates in the FGA region are $4.8 \times 10^{-13} \mathrm{~m} /$ cycle for $n_{\mathrm{L}}=2 \times 10^{6}$, $1.2 \times 10^{-11} \mathrm{~m} /$ cycle for $n_{\mathrm{L}}=1 \times 10^{5}$, and $7.2 \times 10^{-11} \mathrm{~m} /$ cycle for $n_{\mathrm{L}}=1 \times 10^{4}$. The obtained crack growth rates in the FGA region are upwards to connect well with the previously reported crack growth data in FiE region under the same value of $n_{\mathrm{L}}$.

3. As the lower bound of crack growth rate in FGA, the results of equivalent crack growth rates of FGA validate the reasonableness of the directly measured crack growth rates from the captured traces in the FGA region.
4. A layer of nanograins prevails in the FGA region for the specimens under VA cycling with both RB and ER method, which is a new evidence to support the validity of the previously proposed NCP model in the case of VHCF under VA cycling.

\section{ACKNOWLEDGEMENTS}

This experimental investigation was supported by the National Natural Science Foundation of China (11572325) and by the Strategic Priority Research Program of the Chinese Academy of Sciences (XDB22040503, XDB22020201).

\section{ORCID}

Youshi Hong (ID http://orcid.org/0000-0003-3425-6808

\section{REFERENCES}

1. Marines I, Bin X, Bathias C. An understanding of very high cycle fatigue of metals. Int J Fatigue. 2003;25(9-11):1101-1107.

2. Murakami Y, Yokoyama NN, Nagata J. Mechanism of fatigue failure in ultralong life regime. Fatigue Fract Eng Mater Struct. 2002;25(8-9):735-746.

3. Zimmermann M. Diversity of damage evolution during cyclic loading at very high numbers of cycles. Mater Sci Res. 2012;57:73-91.

4. Sakai T. Review and prospects for current studies on very high cycle fatigue of metallic materials for machine structural use. J Solid Mech Mater Eng. 2009;3(3):425-439.

5. Krupp U, Giertler A, Koschella K. Microscopic damage evolution during very high cycle fatigue (VHCF) of tempered martensitic steel. Fatigue Fract Eng Mater Struct. 2017;40(11): 1731-1740.

6. Mayer H. Recent developments in ultrasonic fatigue. Fatigue Fract Eng Mater Struct. 2016;39(1):3-29.

7. Hong Y, Zhao A, Qian G, Zhou C. Fatigue strength and crack initiation mechanism of very-high-cycle fatigue for low alloy steels. Metall Mater Trans a. 2012;43A:2753-2762. 
8. Shiozawa K, Morii Y, Nishino S, Lu L. Subsurface crack initiation and propagation mechanism in high-strength steel in a very high cycle fatigue regime. Int J Fatigue. 2006;28(11):1521-1532.

9. Chai G. Analysis of microdamage in a nickel-base alloy during very high cycle fatigue. Fatigue Fract Eng Mater Struct. 2016;39(6):712-721.

10. Lei Z, Hong Y, Xie J, Sun C, Zhao A. Effects of inclusion size and location on very-high-cycle fatigue behavior for high strength steels. Mater Sci Eng a. 2012;558:234-241.

11. Liu X, Sun C, Hong Y. Faceted crack initiation characteristics for high-cycle and very-high-cycle fatigue of a titanium alloy under different stress ratios. Int J Fatigue. 2016;92:434-441.

12. Sakai T, Lian B, Takeda M, et al. Statistical duplex S-N characteristics of high carbon chromium bearing steel in rotating bending in very high cycle regime. Int J Fatigue. 2010;32(3): 497-504.

13. Grad P, Kerscher E. Reason for the transition of fatigue crack initiation site from surface to subsurface inclusions in high-strength steels. Fatigue Fract Eng Mater Struct. 2017;40(11):1718-1730.

14. Sakai T, Sato Y, Oguma N. Characteristic S-N properties of highcarbon-chromium-bearing steel under axial loading in long-life fatigue. Fatigue Fract Eng Mater Struct. 2002;25(8-9):765-773.

15. Murakami Y, Nomoto T, Ueda T. Factors influencing the mechanism of superlong fatigue failure in steels. Fatigue Fract Eng Mater Struct. 1999;22(7):581-590.

16. Shiozawa K, Lu L, Ishihara S. S-N curve characteristics and subsurface crack initiation behaviour in ultra-long life fatigue of a high carbon-chromium bearing steel. Fatigue Fract Eng Mater Struct. 2001;24(12):781-790.

17. Hong Y, Lei Z, Sun C, Zhao A. Propensities of crack interior initiation and early growth for very-high-cycle fatigue of high strength steels. Int J Fatigue. 2014;58:144-151.

18. Pineau A, Forest S. Effect of inclusions on the very high cycle fatigue of steels. Fatigue Fract Eng Mater Struct. 2017;40:16941707.

19. Murakami Y, Nomoto T, Ueda T, Murakami Y. On the mechanism of fatigue failure in the superlong life regime $(\mathrm{N}>10(7)$ cycles). Part I: influence of hydrogen trapped by inclusions. Fatigue Fract Eng Mater Struct. 2000;23:893-902.

20. Murakami Y, Nomoto T, Ueda T, Murakami Y. On the mechanism of fatigue failure in the superlong life regime $(\mathrm{N}>10(7)$ cycles). Part II: a fractographic investigation. Fatigue Fract Eng Mater Struct. 2000;23:903-910.

21. Sakai T, Oguma N, Morikawa A. Microscopic and nanoscopic observations of metallurgical structures around inclusions at interior crack initiation site for a bearing steel in very high-cycle fatigue. Fatigue Fract Eng Mater Struct. 2015;38(11): 1305-1314.

22. Grad P, Reuscher B, Brodyanski A, Kopnarski M, Kerscher E. Mechanism of fatigue crack initiation and propagation in the very high cycle fatigue regime of high-strength steels. Scripta Mater. 2012;67(10):838-841.

23. Shanyavskiy AA. Mechanisms and modeling of subsurface fatigue cracking in metals. Eng Fract Mech. 2013;110:350-363.
24. Hong Y, Liu X, Lei Z, Sun C. The formation mechanism of characteristic region at crack initiation for very-high-cycle fatigue of high-strength steels. Int J Fatigue. 2016;89:108-118.

25. Su H, Liu X, Sun C, Hong Y. Nanograin layer formation at crack initiation region for very-high-cycle fatigue of a Ti-6Al-4V alloy. Fatigue Fract Eng Mater Struct. 2017;40(6):979-993.

26. Hong Y, Sun C. The nature and the mechanism of crack initiation and early growth for very-high-cycle fatigue of metallic materials-an overview. Theor Appl Fract Mech. 2017;92:331-350.

27. Elber W. Fatigue crack closure under cyclic tension. Eng Fract Mech. 1970;2:37-45.

28. Pippan R, Hohenwarter A. Fatigue crack closure: a review of the physical phenomena. Fatigue Fract Eng Mater Struct. 2017;40(4):471-495.

29. Ainsworth RA, Sharples JK, Smith SD. Effects of residual stresses on fracture behaviour-experimental results and assessment methods. J Strain Anal Eng. 2000;35(4):307-316.

30. Farahani M, Sattari-Far I, Akbari D, Alderliesten R. Effect of residual stresses on crack behaviour in single edge bending specimens. Fatigue Fract Eng Mater Struct. 2013;36(2):115-126.

31. Jiang Q, Sun C, Liu X, Hong Y. Very-high-cycle fatigue behavior of a structural steel with and without induced surface defects. Int J Fatigue. 2016;93:352-362.

32. Tanaka K, Akiniwa Y. Fatigue crack propagation behaviour derived from S-N data in very high cycle regime. Fatigue Fract Eng Mater Struct. 2002;25(8-9):775-784.

33. Stanzl-Tschegg S, Schonbauer B. Near-threshold fatigue crack propagation and internal cracks in steel. Procedia Eng. 2010;2(1):1547-1555.

34. Ishida W, Yamamoto T, Kaneda S, Ogawa T. Fatigue strength and internal crack growth behavior of high strength steel under variable amplitude stressing in very high cycle regime. JSME Int J, Ser B. 2012;78:23-33.

35. Ogawa T, Stanzl-Tschegg SE, Schoenbauer BM. A fracture mechanics approach to interior fatigue crack growth in the very high cycle regime. Eng Fract Mech. 2014;115:241-254.

36. Muller T, Sander M. On the use of ultrasonic fatigue testing technique-variable amplitude loadings and crack growth monitoring. Ultrasonics. 2013;53(8):1417-1424.

37. Sander M, Muller T, Lebahn J. Influence of mean stress and variable amplitude loading on the fatigue behaviour of a high-strength steel in VHCF regime. Int J Fatigue. 2014;62:10-20.

38. Sander M, Muller T, Stacker C. Very high cycle fatigue behavior under constant and variable amplitude loading. Procedia Struct Inte. 2016;2:34-41.

39. Lei Z, Xie J, Sun C, Hong Y. Effects of loading condition on very-high-cycle fatigue behaviour and dominant variable analysis. Sci China Phys Mech. 2014;57(1):74-82.

40. Sun C, Zhang X, Liu X, Hong Y. Effects of specimen size on fatigue life of metallic materials in high-cycle and very-high-cycle fatigue regimes. Fatigue Fract Eng Mater Struct. 2016;39(6):770-779.

41. Miner MA. Cumulative damage in fatigue. J Appl Mech-T Asme. 1945;12:A159-A164. 
42. Murakami Y, Kodama S, Konuma S. Quantitative-evaluation of effects of non-metallic inclusions on fatigue-strength of high-strength steels .1. Basic fatigue mechanism and evaluation of correlation between the fatigue fracture-stress and the size and location of non-metallic inclusions. Int $J$ Fatigue. 1989;11(5):291-298.

43. Zhao A, Xie J, Sun C, Lei Z, Hong Y. Effects of strength level and loading frequency on very-high-cycle fatigue behavior for a bearing steel. Int J Fatigue. 2012;38:46-56.

44. Hertzberg RW. Deformation Fracture Mechanics of Engineering Materials. USA: Wiley; 1995.

\section{APPENDIX}

Table A1 Testing parameters and experimental data for specimens via VA cycling with RB and ER machine
45. Zhao A, Xie J, Sun C, Lei Z, Hong Y. Prediction of threshold value for FGA formation. Mater Sci Eng a. 2011;528(22-23): 6872-6877.

How to cite this article: $\mathrm{Hu}$ Y, Sun $\mathrm{C}$, Hong Y. Crack growth rates and microstructure feature of initiation region for very-high-cycle fatigue of a high-strength steel. Fatigue Fract Eng Mater Struct. 2018;41:1717-1732. https://doi.org/10.1111/ ffe. 12811

\begin{tabular}{|c|c|c|c|c|c|c|}
\hline Specimen code & $\sigma_{\mathrm{L}, \max }, \mathrm{MPa}$ & $\sigma_{\mathrm{H}, \max }, \mathrm{MPa}$ & $n_{\mathrm{L}}$ & $n_{H}$ & $n_{\mathrm{H}} / n_{\mathrm{L}}$ & $\boldsymbol{N}_{\mathrm{f}}$ \\
\hline RB-2 & 800 & 1000 & $2 \times 10^{6}$ & $2 \times 10^{4}$ & 0.01 & $3.71 \times 10^{8}$ \\
\hline RB-3 & 850 & 1000 & $2 \times 10^{6}$ & $2 \times 10^{4}$ & 0.01 & $1.41 \times 10^{8}$ \\
\hline RB-4 & 850 & 1000 & $2 \times 10^{6}$ & $2 \times 10^{4}$ & 0.01 & $2.24 \times 10^{7}$ \\
\hline RB-7 & 750 & 950 & $1 \times 10^{5}$ & $5 \times 10^{3}$ & 0.05 & $9.13 \times 10^{7}$ \\
\hline RB-8 & 800 & 1000 & $1 \times 10^{5}$ & $5 \times 10^{3}$ & 0.05 & $4.41 \times 10^{7}$ \\
\hline RB-9 & 800 & 1000 & $1 \times 10^{5}$ & $1 \times 10^{3}$ & 0.01 & $1.22 \times 10^{7}$ \\
\hline RB-13 & 750 & 900 & $2 \times 10^{6}$ & $2 \times 10^{5}$ & 0.10 & $1.73 \times 10^{7}$ \\
\hline RB-14 & 750 & 900 & $2 \times 10^{6}$ & $2 \times 10^{5}$ & 0.10 & $1.97 \times 10^{7}$ \\
\hline RB-15 & 750 & 900 & $2 \times 10^{6}$ & $2 \times 10^{5}$ & 0.10 & $1.31 \times 10^{8}$ \\
\hline RB-16 & 700 & 850 & $2 \times 10^{6}$ & $2 \times 10^{5}$ & 0.10 & $2.30 \times 10^{8}$ \\
\hline RB-17 & 800 & 1000 & $1 \times 10^{4}$ & $1 \times 10^{3}$ & 0.10 & $4.23 \times 10^{6}$ \\
\hline RB-18 & 750 & 1000 & $1 \times 10^{4}$ & $1 \times 10^{3}$ & 0.10 & $2.02 \times 10^{7}$ \\
\hline RB-19 & 750 & 900 & $1 \times 10^{4}$ & $1 \times 10^{3}$ & 0.10 & $1.36 \times 10^{8}$ \\
\hline RB-20 & 750 & 950 & $1 \times 10^{4}$ & $1 \times 10^{3}$ & 0.10 & $2.65 \times 10^{7}$ \\
\hline
\end{tabular}

